\section{Sleepless Harvest}

SIR,--In the account of some factors affecting beard growth in a male subject (Nature, May 30, p. 869), no evidence is adduced that it is the growth of facial hair that is being measured. What the author has shown is that, under different conditions, variations occur in the amount of beard hair that is harvested. It is well known that the amount of tissue fluid in the face has a marked influence on the quantity of facial hair that can be harvested by shaving ${ }^{1}$ and it may prove that the observations of your correspondent are indicative of changes in the fluid balanee of the facial skin under the conditions described. Some idea of the fluid content of the facial skin may be obtained from measurements of car lobe thickness ${ }^{1}$. Not only hormones, but the body posture may modify the amount of tissue fluid in the face, so it would be of interest to discover if, for example, a restless night influences the amount of beard that can be shaved next morning.

$$
\text { Yours faithfully, }
$$

\section{S. Parsons}

Department of Biochemistry, University of Oxford.

${ }^{1}$ Vorel, D., J. Physiol., 130, 72 (1955).

\section{A Leaf from Lysistrata}

SrR,-Your anonymous correspondent (Nature, May 30 , p. 869) ought, in the interests of seience, to try abstaining from sexual activity during some of his returns to civilization. Or, better still, the lady concerned might be persuaded to cooperate in the experiment by unexpectedly withholding her favours during certain of his visits, chosen at random.

There are likely to be many other variables differentiating his way of life on this remote island from the mainland, and without some such control the evidence so far adduced would seem insufficient to prove that it is sexual intercourse, and its anticipation, which really is the factor responsible for the observed increase in beard growth, however attractive this hypothesis may appear to be for endocrinological reasons.

\section{Yours faithfully,}

\section{B. GoOdhaRt}

Department of Zoology,

University of Cambridge.

\section{When Desire Fails}

Sir,--Anon (Nature, May 30, p. 869) has destroyed his own argument in his final paragraph by stating that the androgen is released "in anticipation of intercourse", and this is confirmed by his graphs which also show decreasing beard growth during the total period of sexual activity.

Earlier he observes that "Tension, anxiety, nervousness, excessive mental fatigue and alcohol consumption were all associated with increased beard growth, while excessive physical exercise and high ambient temperatures seemed to inhibit growth".

The increascd beard growth rate is not therefore a direct androgen effect so much as a stimulation directly due to emotion, and therefore probably mediated by ACTH release, via adrenal hormones.

I am surprised that he finds excessive mental fatigue to have a stimulating effect, since this, like excessive physical exercise and other forms of severe stress, effectivoly inhibits all sexual desire, and can cause complete impotence.
It seems therefore that slight emotional stress may have a stimulating effect on beard growth, while more severc stress is inhibitory. This corresponds closely with stress effects on other glands, such as salivary and digestive glands, where slight emotional stress has a stimulating effect, whereas groater stress is inhibitory.

\section{Yours faithfully-}

\section{H. A. COOK}

The Clinic for Nervous Disorders, 14 St Alban's Street, Jermyn Street, London SW1.

These letters have been shown to the author of the article concerned, who comments as follows:

I would be the first to admit that beard growth is influenced by a multiplicity of factors, and I am well aware of the limitations of woighing shavings to indicate the rate of beard growth. Variation in facial oedema as $\approx$. consequence of changes in posture and activity undoubt edly influence the effectiveness of shaving. I attempted to control these factors by adopting a standardized shaving technique; I always shaved whilo standing, within 30 minutes of getting out of bed in the morning and before washing. By collecting samples every 24 hours many of the minor variations were eliminated. In addition observations were made under a great variety of circum. stances when skin texture alone could not explain the ehanges in beard weight.

When shaving twice a day, at 9 a.m. and 9 p.m., the evening sample was always heavier, and this could have been due to alterations in skin hydration. However, a marked increase in the weight of the evening sample always presaged the resumption of sexual activity at night, even though the day's routine had remained unchanged. It was curious that regardless of my activities, my rate of beard growth was eontinually higher on the mainland than while on the island.

To me the most interesting finding was that beard growth was stimulated by the anticipation of intercourse, but that it subsequently declined even though sexual relations were maintained. This stimulatory effect was undoubtedly accentuated by a prolonged period of isolation, followed by the intense excitement of courtship behaviour. It may be significant that experiments now being performed by some of my colleagues have established that in cattle the sight of the cow is a potent stimuIus for LH release and testosterone secretion in the bull, whereas intercourse and orgasm is not.

It is obviously necessary to verify my hypothesis by carrying out some blood testosterone determinations on myself. The poor correlation between hair growth and urinary ketosteroid excretion referred to by Professor Bullough is hardly surprising, as ketosteroids are a notoriously inadequate index of testosterone secretion in man. Although there is a vast literature on the effect of androgens on hair growth in animals; almost all the studies relate to general body hair which is not a male secondary sexual characteristic. However, if one studies the effects of androgens on secondary sexual hair, such as the neck mane of the red deer stag, the intimate hormonal dependence is obvious.

Of all the factors that I have found which influence my beard growth, it seems significant that the stimulation associated with a resumption in sexual activity is far greater than that produced by anything else.

No doubt when sexual relationships become unpremeditated commonplace activity after I am married, I will become as sceptical of my early findings as your distinguished correspondents appear to be. 